\title{
Bertalanffy-Pütter Models for the Growth of Tropical Trees and Stands
}

\author{
Norbert Brunner, Manfred Kühleitner \\ Department of Integrative Biology and Biodiversity Research (DIBB), University of Natural Resources and Life Sciences (BOKU), \\ Vienna, Austria \\ Email: norbert.brunner@boku.ac.at, manfred.kuehleitner@boku.ac.at
}

How to cite this paper: Brunner, N. and Kühleitner, M. (2020) Bertalanffy-Pütter Models for the Growth of Tropical Trees and Stands. Open Journal of Modelling and Simulation, 8, 73-87.

https://doi.org/10.4236/ojmsi.2020.84006

Received: July 30, 2020

Accepted: September 4, 2020

Published: September 7, 2020

Copyright (c) 2020 by author(s) and Scientific Research Publishing Inc. This work is licensed under the Creative Commons Attribution International License (CC BY 4.0).

http://creativecommons.org/licenses/by/4.0/

(c) (i) Open Access

\begin{abstract}
The Bertalanffy-Pütter (BP) five-parameter growth model provides a versatile framework for the modeling of growth. Using data from a growth experiment in literature about the average size-at-age of 24 species of tropical trees over ten years in the same area, we identified their best-fit BP-model parameters. While different species had different best-fit exponent-pairs, there was a model with a good fit to $21(87.5 \%)$ of the data ("Good fit" means a normalized root-mean-squared-error NRMSE below 2.5\%. This threshold was the 95\% quantile of the lognormal distribution that was fitted to the NRMSE values for the best-fit models for the data). In view of the sigmoidal character of this model despite the early stand we discuss whether the setting of the growth experiment may have impeded growth.
\end{abstract}

\section{Keywords}

Bertalanffy-Pütter (BP) Differential Equation, Growth Model, Normalized

Root-Mean-Squared-Error (NRMSE), Simulated Annealing

\section{Introduction}

There are multiple factors that influence the growth of trees and forest stands [1] and therefore also a variety of growth equations used in forest science [2] [3] [4] and [5]. Practitioners often use simple three-parameter models, e.g. of Brody [6], Gompertz [7], or Verhulst [8], as these are numerically tractable. The four-parameter Chapman-Richards growth function [9] is popular, too (110,000 hits in Google Scholar). However, the use of many different growth models makes the comparison of the outcomes difficult. Therefore, here we consider the five-parameter Bertalanffy-Pütter (BP) model, as it generalizes these models and provides a more unified approach using growth curves with better fits to the data. 
We ask, if a further unification is possible, provided that the environment is the same: Is there a three-parameter BP-model that fits well to most growth data (with different optimal parameters for each data), provided that the growth conditions for all trees are the same? We illustrate this question for growth data from Devaranavadgi [10] about the average heights of 24 species of tropical trees that were grown on dry and shallow soil. Table 1 provides the data. The data represent the first 11 years of an early forest stand with final mean heights for the species between 2.56 and $9.60 \mathrm{~m}$. We therefore assume that for each species

Table 1. Species and data.

\begin{tabular}{|c|c|c|c|c|c|c|c|c|c|c|c|c|c|c|}
\hline \multirow{2}{*}{ No. } & \multicolumn{2}{|c|}{ Name } & \multirow{2}{*}{$\begin{array}{l}\operatorname{Max}^{1} \\
\text { in } m\end{array}$} & \multicolumn{11}{|c|}{ height at age data (height in $\mathrm{cm}$, rounded to 0 decimals; year at bottom) ${ }^{2}$} \\
\hline & common & Species & & $h_{1}$ & $h_{2}$ & $\boldsymbol{h}_{3}$ & $h_{4}$ & $h_{5}$ & $h_{6}$ & $h_{7}$ & $h_{8}$ & $h_{9}$ & $h_{10}$ & $h_{11}$ \\
\hline T01 & ear-pod wattle & Acacia auriculiformis & $15-30$ & 52 & 81 & 141 & 241 & 319 & 370 & 450 & 532 & 590 & 640 & 680 \\
\hline T02 & black cutch & Acacia catechu & 15 & 46 & 61 & 123 & 185 & 251 & 292 & 349 & 391 & 416 & 421 & 430 \\
\hline T03 & gum-arabica tree & Acacia nilotica & $20-25$ & 48 & 68 & 123 & 175 & 271 & 324 & 383 & 440 & 470 & 522 & 544 \\
\hline T04 & river tamarind & Leucaena leucocephala & $2-10$ & 38 & 63 & 166 & 272 & 381 & 491 & 572 & 761 & 864 & 920 & 960 \\
\hline T05 & Indian siris & Albizzia lebbeck & $18-30$ & 15 & 83 & 181 & 281 & 372 & 469 & 530 & 572 & 601 & 644 & 663 \\
\hline T06 & neem & Azadirachta indica & $15-20$ & 34 & 83 & 126 & 189 & 253 & 329 & 388 & 421 & 456 & 497 & 521 \\
\hline T07 & orchid tree & Bahunia purpurea & 5 & 64 & 83 & 149 & 201 & 251 & 321 & 376 & 419 & 455 & 471 & 489 \\
\hline T08 & bastard teak & Buteo monosperma & $6-12$ & 11 & 29 & 69 & 101 & 150 & 184 & 211 & 231 & 249 & 259 & 269 \\
\hline T09 & beach oak & Casuarina equisitefolia & $6-35$ & 95 & 114 & 134 & 178 & 230 & 281 & 312 & 350 & 372 & 390 & 404 \\
\hline $\mathrm{T} 10$ & ironwood & Senna siamea & 18 & 69 & 91 & 138 & 181 & 223 & 275 & 337 & 372 & 419 & 457 & 481 \\
\hline T11 & Indian rosewood & Dalbergia sissoo & $10-15$ & 52 & 85 & 149 & 201 & 265 & 313 & 351 & 399 & 431 & 442 & 451 \\
\hline T12 & red flame-tree & Delonix regia & $12-17$ & 16 & 31 & 69 & 121 & 163 & 193 & 231 & 252 & 273 & 281 & 302 \\
\hline $\mathrm{T} 13$ & Indian goose-berry & Emblica officianalis & $8-23$ & 83 & 135 & 188 & 279 & 343 & 406 & 511 & 568 & 603 & 612 & 624 \\
\hline $\mathrm{T} 14$ & $\begin{array}{l}\text { lemon-scented } \\
\text { eucalyptus }\end{array}$ & Eucalyptus citriodara & 30 & 79 & 176 & 283 & 373 & 465 & 589 & 641 & 742 & 812 & 864 & 885 \\
\hline T15 & some eucalyptus & Eucalyptus hybrid & - & 82 & 123 & 184 & 282 & 341 & 494 & 529 & 572 & 589 & 621 & 649 \\
\hline T16 & anjan tree & Hardwickia binata & $25-30$ & 31 & 73 & 146 & 209 & 259 & 311 & 355 & 478 & 539 & 562 & 591 \\
\hline T17 & axle-wood & Anogeissus latifolia & 20 & 38 & 62 & 124 & 182 & 239 & 331 & 388 & 446 & 486 & 519 & 591 \\
\hline T18 & sweet inga & Pithecellobium dulce & $5-20$ & 81 & 123 & 179 & 221 & 279 & 334 & 386 & 429 & 461 & 499 & 519 \\
\hline T19 & yellow flame-tree & Peltoferrum ferrugeneum & $15-25$ & 22 & 31 & 172 & 317 & 395 & 463 & 472 & 457 & 481 & 508 & 529 \\
\hline $\mathrm{T} 20$ & Indian beech & Millettia pinnata & $15-25$ & 13 & 49 & 109 & 182 & 234 & 289 & 356 & 406 & 442 & 477 & 496 \\
\hline $\mathrm{T} 21$ & mesquite & Prosopsis juliflora & 12 & 96 & 135 & 197 & 262 & 311 & 362 & 399 & 441 & 471 & 492 & 503 \\
\hline $\mathrm{T} 22$ & raintree & Samanea saman & $15-25$ & 68 & 101 & 159 & 206 & 266 & 313 & 354 & 391 & 423 & 454 & 468 \\
\hline $\mathrm{T} 23$ & black plum & Syzygium cumini & $6-20$ & 58 & 72 & 98 & 136 & 165 & 172 & 192 & 209 & 233 & 246 & 256 \\
\hline \multirow[t]{3}{*}{$\mathrm{T} 24$} & tamarind & Tamarindus indica & 30 & 37 & 49 & 89 & 129 & 178 & 209 & 237 & 270 & 296 & 313 & 321 \\
\hline & \multicolumn{2}{|c|}{ year } & & ‘90 & ‘91 & ‘92 & ‘93 & ‘94 & ‘95 & ‘96 & ‘97 & ‘98 & ‘99 & ‘00 \\
\hline & \multicolumn{2}{|c|}{ mean annual temperature $\left({ }^{\circ} \mathrm{C}\right)^{3}$} & & 26.5 & 27.1 & 27.6 & 27.5 & 27.4 & 27.8 & 28.2 & 28.1 & 28.2 & 27.9 & 27.6 \\
\hline
\end{tabular}

Note: ${ }^{1}$ typical maximal heights (from diverse sources); ${ }^{2}$ data from Devaranavadgi [10], ${ }^{3}$ data from Belgaum airport (VABM weather station, $200 \mathrm{~km}$ SW of Vijaya Pura) and retrieved using Mathematica 12.1 for "Bijapur, Karnataka, India". 
the data represent the initial growth phase of the trees, whence BP-models are suitable. Note that all mentioned models have none or one inflection point; in the latter case the growth curves are sigmoidal (S-shaped). The growth curve of a tree may display several inflection points, each representing another sigmoidal growth phase, c.f. [11] and [12], whence a single sigmoidal growth curve is capable of modeling only one of these phases.

For each species we identify the best-fit parameters for the BP-model, from which we compute additional parameters with a silvicultural relevance, such as the location of the inflection point (maximal yearly growth) and asymptotic height (final expected size of the first growth phase). As to the above-mentioned research question, we speculate that the experimental setup of the growth study, from which we have taken the data, may have impeded the growth of most trees. For, the analysis of the inflection points indicates an early slowing down of growth (unexpected at this early phase) and we identified a single three-parameter model that had a "good fit" (defined later) to most data.

As for another application, we use these models to check if temperature has affected tree growth. For, in temperate climate, higher temperatures enhance growth, while in tropical climate growth slows down [13] [14].

\section{Materials and Methods}

\subsection{Data}

We used the literature data of Table 1 (see also Figure 5) from Devaranavadgi [10]: An unspecified number of trees from 24 species was planted in 1990 and tree heights were measured annually till 2000 (11 data per species). The table informs about the species T01 - T24 and reports their average-height-at-age data (The source paper provides additional information, such as soil composition. There is no information about the standard deviation of the heights). The data are of additional interest, as often tree size is measured by other parameters [15]. Table 1 also informs about the annual mean temperatures (for 1990, ..., 1999) for the larger region around Vijaya Pura. We used Mathematica to retrieve them from the Wolfram Alpha database.

The growth data were obtained during a study at the Regional Agricultural Research Station of Vijaya Pura (district Bijapur, Karnataka, India), located in the Deccan plateau. Figure 1 pinpoints the study site. It has a semi-arid climate with temperatures ranging from $15^{\circ} \mathrm{C}$ to $42^{\circ} \mathrm{C}$ and average annual rainfall of 594 $\mathrm{mm}$ with 39 rainy days. The region suffers from deforestation owing to poor management practices, low fertility of soil, and a harsh climate [16]. The study therefore searched for species with added economic or ecological value that were suitable for re-forestation. Note that some of the species that the study considered may become invasive in more humid areas (e.g. mesquite).

\subsection{Growth Model}

The Bertalanffy-Pütter (BP) model describes tree growth by means of the differential 


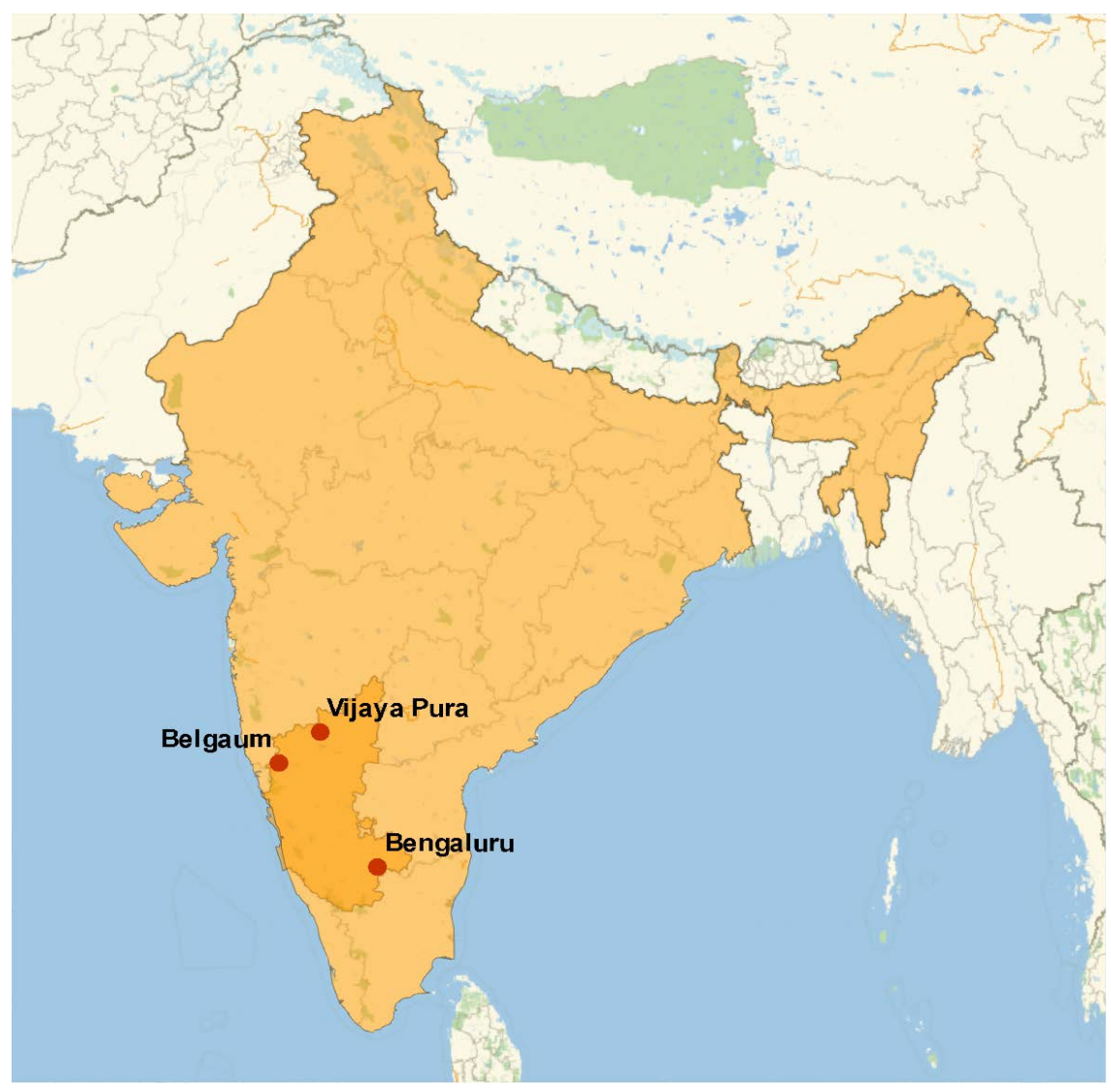

Figure 1. Plot of India and of Karnataka state (shades of beige), and in red the study site Vijaya Pura, the airport at Belaum, and of the state capital Bengaluru (Bangalore). Plot using Mathematica 12.1, based on Open Street Map (the plotted boundaries are neither endorsed by the authors nor may they be correct).

Equation (1) of Pütter [17] for the tree height $h(t)$ at time $t$. The differential equation can be solved analytically, though in general not by means of elementary functions [18].

$$
h^{\prime}(t)=p \cdot h(t)^{a}-q \cdot h(t)^{b}
$$

Tree growth models for temperate climates often use difference equations, i.e. the derivative $h^{\prime}(t)$ in Equation (1) is replaced by the difference $h(t+1)-h(t)$. In temperate climates this assumption is warranted, as the sharp seasonal changes are apparent from the growth rings. We use the differential equation, as we consider tropical trees. Further, the yearly growth data showed random fluctuations, while the height-at-age data used for the fitting of model (1) were comparably smooth.

The model parameters of Equation (1) have no meaning a priori. They are to be determined from fitting the model to height-at-age data: Four parameters are displayed in the equation, namely the exponent-pair $a<b$ and the scaling constants $p$ and $q$. An additional parameter is the initial value at age 1, meaning $h(1)=c>0$. While in forestry literature also negative exponents were considered $(a<0, b=1)$, as thereby a growth model of Schnute [19] would fit into the 
BP-framework [20], this paper assumes non-negative exponents.

In this form, the BP-model was popularized by Bertalanffy [21] [22] [23] as a model of ontogenetic growth. According to Bertalanffy, the growth of animals, plants and biomass would be governed by certain biophysical principles, which in their most general form would be embodied by Equation (1). Specifically, the growth of trees would be based on an allometric relation between living biomass and photosynthetic area [24], whereby the exponent-pair $(a, b)$ would be related to plant metabolism.

Each exponent-pair $(a, b)$ defines a unique three-parameter model $\mathrm{BP}(a, b)$, using the parameters $p, q, c$. For comparison, Figure 2 plots the exponent-pairs of well-known models and compares them with the exponent-pairs that this paper scanned in an initial search for the optimal model parameters.

Common named three-parameter models are the Brody [6] (monomolecular) model $\mathrm{BP}(0,1)$ of bounded exponential growth, the Verhulst [7] model of logistic growth $\mathrm{BP}(1,2)$, the model $\mathrm{BP}(2 / 3,1)$ of von Bertalanffy [21], or the model $\mathrm{BP}(3 / 4,1)$ of West [25]. Four-parameter models that are special cases of equation (1) are the generalized Bertalanffy model $(b=1, a<1)$ and the Richards [9] model ( $a=1, b>1$ ). The Gompertz [7] model is the limit case $\mathrm{BP}(1,1)$ with a different differential equation, where $b$ converges to $a=1$ from above [26]; similarly for the generalized Gompertz model (model class $a=b$ ) with Equation (2):

$$
h^{\prime}(t)=p \cdot h(t)^{a}-q \cdot \ln (h(t)) \cdot h(t)^{a}
$$

Note that $\mathrm{BP}(1,1)$ is attractive amongst botanists, as the same model (with different parameters $c, p, q$ ) is capable of describing different dimensions of plant-growth (e.g. height, basal area, volume), provided that there exists an allometric relation between these dimensions. The other models do not have this property (i.e. different exponent-pairs are needed for different dimensions).

Alternative parametrizations of the model use empirically meaningful parameters, such as the asymptotic height $h_{\max }$ (limit of the height at infinite time) or

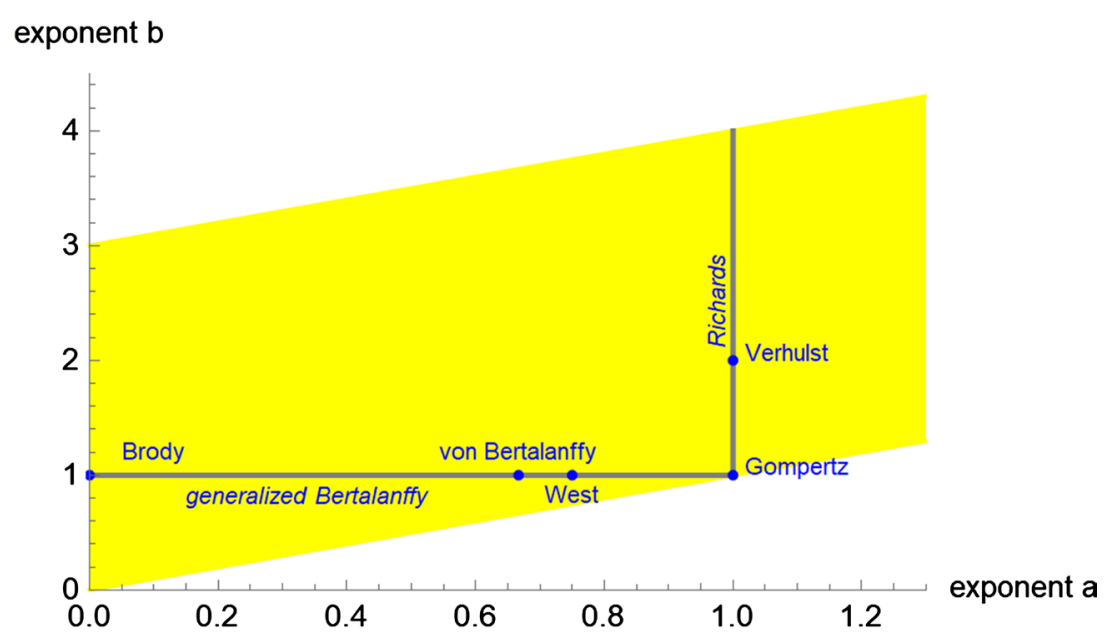

Figure 2. Special models (blue dots), model classes (grey lines), and the initial search grid (yellow). Plot using Mathematica 12.1. 
the inflection point (height $h_{\text {inf }}$ reached at age $t_{\text {inff }}$ ). Asymptotic height is an important silvicultural measure, as it allows to assess the ultimate yield. It depends both on the species and on the environment, where the tree was planted. The inflection point informs when growth was fastest. The maximal annual growth rate is important for plant biology, as it informs about the basal metabolic rate [27]. These parameters are computed from the parameters of Equation (1) as follows; for $t_{\text {inf }}$ numerical equation solving is used. Growth is unbounded, if $q=0$ and it is not sigmoidal, if $a=0$.

$$
h_{\text {max }}=\left(\frac{p}{q}\right)^{\frac{1}{b-a}} \text { and } h_{\text {infl }}=\left(\frac{a}{b}\right)^{\frac{1}{b-a}} \cdot h_{\text {max }}
$$

Some authors [28] were concerned that asymptotic length would be unreliable if it exceeded the maximal observed length substantially. We therefore compared $h_{\max }$ with typical tree heights.

\subsection{Goodness of Fit and Method of Calibration}

We sought for parameters that minimized $S S E$, the sum of squared errors for fitting the BP-growth function to height-at-age-data. If $h(t)$ is a solution of Equation (1), using certain exponents $a<b$ and parameters $p, q, c$, and if $h_{i}$ are the $n$ $=11$ average weights, then $S S E$ is defined by Equation (4):

$$
S S E=\sum_{i=1}^{11}\left(h_{i}-h(i)\right)^{2}
$$

The data-fitting exercise for the BP-model is more challenging than for the Richards model, where standard optimization routines may run into difficulties [29]. In recent papers a method of data-fitting was developed for the BP-model [30] [31] [32] and [33]. This method was based on a grid-search, whereby we searched the best-fitting exponent-pairs $(a, b)$ on a grid with step size 0.01 in both directions (Figure 1). For each grid point we identified the best fitting model parameters $(p, q, c)$ that minimized $S S E$ using a custom-made variant of the method of simulated annealing [34]. Simulated annealing alone could be used to optimize for all five parameters $(a, b, p, q, c)$ at once, but often the so computed parameters achieved a suboptimal fit. Note that we optimized also for the initial values $c$, whence in Table 2 the best-fit values for $c$ slightly differed from the observed initial heights $h_{1}$ in Table 1 .

For each time series, the best-fit parameters $\left(a_{\min }, b_{\min }, p_{\min }, q_{\min }, c_{\min }\right)$ achieved the least value of $S S E$, namely $S S E_{\text {min }}$. Thereby, for the exponents we aimed at an accuracy of 0.01 (defined from the grid), while the other parameters were identified with a higher accuracy.

Our method of obtaining the five best-fit parameters of the BP-model requires for each dataset the consideration of many three-parameter models whereby for all these models the best-fit parameters need to be computed. We utilize the surplus information from this approach and ask, if one three-parameter model would fit for all (or for most) species, if the notion of "fit" was somewhat relaxed; i.e. 
Table 2. Parameters of the best-fit models and measures for the goodness of fit (rounded to 3 decimals).

\begin{tabular}{|c|c|c|c|c|c|c|c|c|c|c|c|}
\hline \multirow{2}{*}{ No. } & \multicolumn{5}{|c|}{ Best-fit parameters ${ }^{1}$} & \multicolumn{3}{|c|}{ Derived parameters ${ }^{2}$} & \multicolumn{3}{|c|}{ Goodness of fit ${ }^{3}$} \\
\hline & $a$ & $b$ & $c$ & $P$ & $q$ & $h_{\max }$ & $h_{\text {infl }}$ & $t_{\text {inf }}$ & $S S E$ & $R M S E$ & NRMSE \\
\hline T01 & 0.83 & 1.02 & 0.435 & 1.720 & 1.137 & 8.839 & 2.987 & 4.909 & 0.101 & 0.096 & $1.4 \%$ \\
\hline T02 & 1.09 & 1.51 & 0.399 & 1.066 & 0.568 & 4.477 & 2.060 & 4.393 & 0.048 & 0.066 & $1.5 \%$ \\
\hline T03 & 1.04 & 1.15 & 0.387 & 2.824 & 2.312 & 6.165 & 2.472 & 4.888 & 0.069 & 0.079 & $1.5 \%$ \\
\hline T04 & 0.30 & 11.12 & 0.242 & 0.756 & $0+$ & 9.601 & 6.876 & 7.594 & 0.309 & 0.167 & $1.7 \%$ \\
\hline T05 & 0.48 & 1.35 & 0.153 & 1.119 & 0.203 & 7.095 & 2.161 & 3.352 & 0.032 & 0.054 & $0.8 \%$ \\
\hline T06 & 0.94 & 1.17 & 0.381 & 1.585 & 1.056 & 5.831 & 2.251 & 4.500 & 0.037 & 0.058 & $1.1 \%$ \\
\hline T07 & 0.60 & 3.18 & 0.590 & 0.429 & 0.007 & 5.060 & 2.651 & 5.126 & 0.031 & 0.053 & $1.1 \%$ \\
\hline T08 & 0.87 & 1.10 & 0.097 & 1.969 & 1.549 & 2.843 & 1.025 & 3.915 & 0.007 & 0.025 & $0.9 \%$ \\
\hline T09 & 1.70 & 2.17 & 0.893 & 0.476 & 0.245 & 4.128 & 2.455 & 5.413 & 0.026 & 0.049 & $1.2 \%$ \\
\hline T10 & 0.69 & 2.50 & 0.667 & 0.358 & 0.016 & 5.566 & 2.733 & 5.915 & 0.017 & 0.040 & $0.8 \%$ \\
\hline T11 & 0.39 & 2.81 & 0.485 & 0.509 & 0.012 & 4.773 & 2.110 & 4.158 & 0.027 & 0.05 & $1.1 \%$ \\
\hline T12 & 0.80 & 1.02 & 0.100 & 1.943 & 1.499 & 3.251 & 1.078 & 3.800 & 0.018 & 0.040 & $1.3 \%$ \\
\hline T13 & 0.32 & 10.25 & 0.813 & 0.527 & $0+$ & 6.200 & 4.373 & 6.203 & 0.062 & 0.075 & $1.2 \%$ \\
\hline T14 & 0.00 & 6.90 & 0.805 & 0.980 & $0+$ & 9.238 & NA & NA & 0.095 & 0.093 & $1.0 \%$ \\
\hline T15 & 1.25 & 1.85 & 0.789 & 0.662 & 0.216 & 6.444 & 3.353 & 4.641 & 0.271 & 0.157 & $2.4 \%$ \\
\hline T16 & 0.21 & 16.74 & 0.352 & 0.524 & $0+$ & 5.876 & 4.509 & 7.880 & 0.235 & 0.146 & $2.5 \%$ \\
\hline T17 & 0.86 & 1.03 & 0.326 & 1.845 & 1.313 & 7.393 & 2.558 & 5.081 & 0.109 & 0.099 & $1.7 \%$ \\
\hline T18 & 0.34 & 3.26 & 0.813 & 0.434 & 0.003 & 5.769 & 2.660 & 4.748 & 0.010 & 0.030 & $0.6 \%$ \\
\hline T19 & 0.68 & 1.31 & 0.003 & 2.095 & 0.761 & 4.992 & 1.763 & 3.031 & 0.314 & 0.169 & $3.2 \%$ \\
\hline T20 & 0.22 & 2.88 & 0.102 & 0.586 & 0.006 & 5.499 & 2.091 & 4.589 & 0.024 & 0.047 & $0.9 \%$ \\
\hline $\mathrm{T} 21$ & 0.94 & 1.33 & 0.929 & 0.927 & 0.476 & 5.515 & 2.265 & 3.503 & 0.015 & 0.037 & $0.7 \%$ \\
\hline T22 & 0.99 & 1.12 & 0.653 & 2.268 & 1.824 & 5.342 & 2.068 & 3.966 & 0.011 & 0.031 & $0.7 \%$ \\
\hline T23 & 0.69 & 0.87 & 0.531 & 1.357 & 1.096 & 3.273 & 0.903 & 2.452 & 0.034 & 0.056 & $2.2 \%$ \\
\hline T24 & 1.05 & 1.21 & 0.313 & 2.120 & 1.732 & 3.528 & 1.454 & 4.391 & 0.020 & 0.043 & $1.3 \%$ \\
\hline
\end{tabular}

Notes: ${ }^{1} 0+$ means a positive number rounded to $0 ;{ }^{2} h_{\max }$ is asymptotic height, $\left(t_{\text {inff }}, h_{\text {inff }}\right)$ is the inflection point (NA for $\left.a=0\right)$; ${ }^{3} R M S E$ is root-meansquared-error, $N R M S E=R M S E / h_{11}$.

"good fit" rather than best fit. We thereby identify, for each species, those exponent-pairs, where the corresponding three-parameter growth model has a "good fit", and then we form the intersection of these 24 (or of fewer) sets. Our definition of a "good fit" is based on the normalized root-mean-squared-error $N R M S E$, as it allows to compare the fit across different species of different height. NRMSE expresses the root-mean-squared-error (RMSE; 11 is the number of data-points) as a percentage of the maximal observed height ( $h_{11}$ of the last data-point):

$$
R M S E=\sqrt{\frac{S S E}{11}} \text { and NRMSE }=\frac{R M S E}{h_{11}}
$$


Further, to define a "good fit" we use a threshold for NRMSE, based on a statistical analysis of the distribution of the observed $N R M S E$-values of the best-fit models. We found that a lognormal distribution would fit to these values (Section 3.2) and we therefore use the threshold corresponding to the 95\% quantile of this distribution. As explained below, for the present data this threshold is $2.5 \%$.

\subsection{Materials}

We used Mathematica 12.1 (Wolfram Research) for computer algebra, including optimization and statistical analysis, and to access meteorological data (Wolfram repository). We used nonparametric methods, as not all data were normally distributed: Spearman rho for rank correlation and Spearman rank test for nonzero correlation (using the permutation method with 1000 Monte-Carlo simulation steps). Where we used a parametric distribution (lognormal distribution), we first tested the distribution assumption using the Anderson-Darling statistic [35] and the threshold of $p=0.05$ (95\% confidence).

\section{Results}

\subsection{Best Fit Parameters}

The size-at-age data of Table 1 (c.f. Figure 5) inform about 11 annual height measurements. It started in 1990 with average heights $h_{1}=11 \mathrm{~cm}$ for "bastard teak" T08 to $96 \mathrm{~cm}$ for mesquite T21 and it ended in 2000 with $h_{11}=2.56 \mathrm{~m}$ for black plum T23 to $9.60 \mathrm{~m}$ for river tamarind T04. Table 2 informs about the growth data, the parameters of the best-fit models, and the goodness of fit.

The best-fit exponent-pairs $(a, b)$ in Table 2 identify those three-parameter models $\operatorname{BP}(a, b)$ that achieved the best fit to the data for T01 to T24. Figure 3

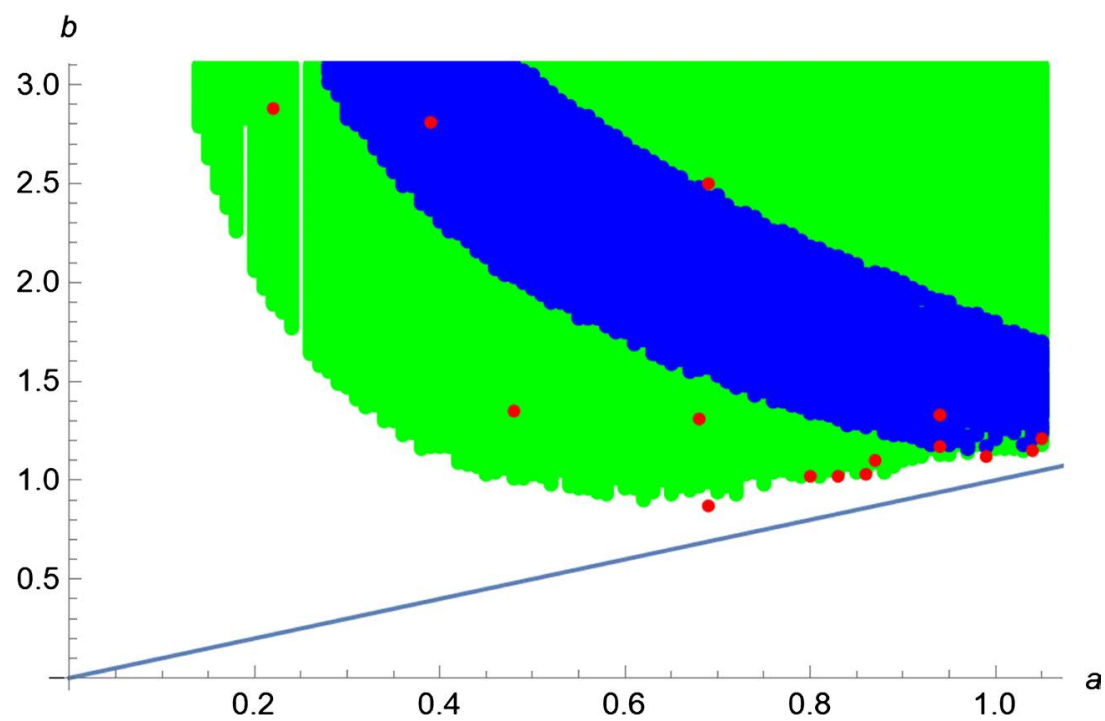

Figure 3. Line $a=b$ (blue) in the region $a<1.05, b<3$ and best-fit exponent-pairs (red), exponent-pairs with NRMSE below $5 \%$ for all data (green), and with NRMSE below $2.5 \%$ for at least 21 data (blue); plot using Mathematica 12.1. 
plots those 15 exponent-pairs that were in the region $a \leq 1.05, b \leq 3$ (Not in the plot were three exponent-pairs with $1.05<a \leq 1.7$ and six exponent-pairs with 3 $<b \leq 16.74)$.

As is evident from this picture, none of these exponent-pairs defined a best-fit model for all data, nor did the exponent-pairs concentrate anywhere. Further, the best-fit exponent-pairs differed clearly from those of the named three-parameter models (i.e. Brody, Gompertz etc.). The distances of these exponent-pairs were smaller to the lines of exponent-pairs defining the four-parameter models, but none of these models was best-fit, either.

Table 2 informs also about derived parameters, asymptotic height $h_{\max }$ and age $t_{\text {inff }}$ and size $h_{\text {inff }}$ of the inflection point. Three-parameter models have the disadvantage that by Equation (3) there is a fixed ratio between the height at the inflection point and asymptotic height, e.g. $50 \%$ ratio $t_{\text {inf }} / h_{\max }$ for logistic growth. By contrast, for the best-fit models either there was no inflection point for one data (lemon-scented eucalyptus T14) or this ratio varied widely between $27.6 \%$ for black plum T23 and 76.7\% for anjan tree T16.

When compared with the sample data, asymptotic height of the best-fit model was in the range of $94 \%-130 \%$ of the maximal observed height $h_{11}$ of Table 1. In view of the Anderson-Darling test, for the present data the quotient $h_{\max } / h_{11}$ was lognormally distributed (no refutation of this hypothesis: $p=0.26$ ). Using the maximum-likelihood estimates for its location and shape parameters $(0.082$ and 0.079 , respectively) we concluded that with $99.5 \%$ probability the maximal projected height of any tree was below $133 \%$ of $h_{11}$. However, except for three species (gum-arabica tree T04, orchid tree T07 and sweet inga T18) the usual heights for trees of the considered species (by Table 1 in most cases $20 \mathrm{~m}$ or more) exceeded the asymptotic heights considerably (e.g. by the factor 3 - 5 for rain tree $\mathrm{T} 22$ ).

\subsection{Defining the Threshold for a Good Fit}

For the best-fit models NRMSE varied between $0.6 \%$ for sweet inga T18 and $3.2 \%$ for yellow flame-tree T19 (Table 2). The good fit was also illustrated by Figure 4, plotting the BP-model curves for gooseberry T13 and yellow flame tree T19.

Using the Anderson-Darling test, the NRMSE-values of Table 2 followed a lognormal distribution (no refutation owing to $p=0.93$ ). We used the maximum-likelihood method to estimate its location and shape parameters $(-4.38$ and 0.42 , respectively). The $95 \%$ quantile of this lognormal distribution led to the threshold $N R M S E=2.5 \%$. We used it to define "good fit". In this sense, the fits of anjan tree T16 and yellow flame-tree T19 were not good. For instance, based on the lognormal distribution, yellow flame-tree T19 was an outlier with a probability of only $1.3 \%$ for $N R M S E>3.2 \%$. Indeed (Figure 4 ), the growth data for T19 were insofar atypical, as height did not always increase (for average data this can occur if e.g. the largest trees are removed) and as growth finally seemed 


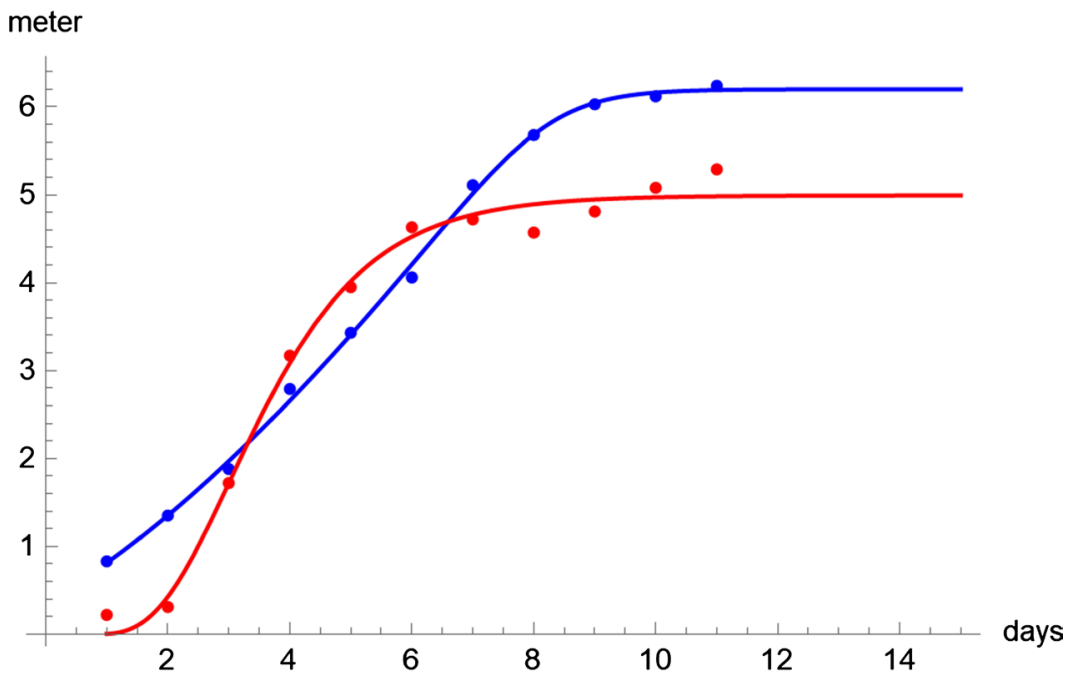

Figure 4. Data and the growth curve for T13 (blue) and T19 (red); plot using Mathematica 12.1 .

to accelerate (e.g. more light for the smaller trees, when the largest ones are removed).

There was no exponent-pair $(a, b)$, where a single model $\mathrm{BP}(a, b)$ could have a good fit to all 24 , to 23 , or to 22 of our data. The maximal number of data with a common good-fitting model was 21: Figure 3 (blue region) plots the exponent-pairs corresponding to models with good fits to 21 of our data (whereby for each data different best-fit parameters $c, p, q$ were used). Most of the best-fit exponent-pairs were outside this region (but for their data NRMSE in general was below 2.5\%). Further, none of the exponent-pairs of the named three-parameter models (e.g. Brody, Gompertz, etc.) was in the blue region of Figure 3. However, the West-model had a good fit to 19 models and amongst the named three-parameter models this was the best outcome.

For comparison, we also considered the threshold 5\%. Using it there were exponent-pairs whose BP-models could be fitted to all data with $N R M S<5 \%$; the green region in Figure 3 plots them. The exponent-pairs $(1,2),(2 / 3,1)$, and $(3 / 4,1)$ of the Verhulst-model, the von-Bertalanffy-model, and the West-model were in the green area, but the exponent-pairs $(0,1)$ and $(1,1)$ of the Brody-model and the Gompertz-model were not.

\subsection{Growth and Temperature}

In order to explore, to what extent the growth was affected by environmental factors (there was no information to this end in the source paper), we used the annual mean temperatures from Table 1 (for 1990, .., 1999) and compared them with the relative growth rates per year: $\left(h_{k+1}-h_{k}\right) / h_{k}$ using $h_{k}$ from Table $1(k=1, \cdots, 10)$. The Spearman rho was negative for all species with values between -0.879 for axle-wood T17 and -0.514 for black plum T23. This was significant for all except four data (Spearman rank test: $p<0.05$ ); the exceptions were ear-pod wattle T01, beach oak T09, anjan tree T16, and black 
plum T23.

Using the BP-model curves allowed to strengthen this finding, namely that for all species there was a highly significant correlation relating higher temperatures to lower percentual growth $h^{\prime} / h$ (but with a delay of one year). Spearman rho had the same value for all data, namely -0.842 , and it was nonzero with high significance for all growth curves (Spearman rank test: $p$-value 0.002).

\section{Discussion and Speculation}

The results of this paper invite two opposite threads for further speculation, namely that perhaps the West model is a universal tree growth model or, alternatively, that perhaps something is wrong with the data.

The former speculation has been forwarded repeatedly in different contexts. For, West [25] [36] [37] [38] [39] developed biophysical arguments in support of the universality of the three-parameter model $\mathrm{BP}(0.75,1)$ for the growth of animals, plants and forests. This claim was often contested as e.g. for trees the biophysical arguments were contingent on additional requirements [40].

However, even using an obviously false universal model may have a rationale, as is illustrated by the practice in fishery science, where the model $\operatorname{BP}(0,1)$, which in general is not the best-fitting model, is used de facto as a universal model for the growth of fish length. A database [41] and [42] collects information about the best-fit parameters for $\operatorname{BP}(0,1)$ for various species of fish in various environments. It has led to new insights, e.g. relating the growth parameters to natural mortality and mean environmental temperature [43]. Because there is no consensus about a common model for the growth of trees, there is no such database yet for the estimated 40,000 species of trees [44]. Considering the present data, the model of West would appear to be suitable for such a database, as it was almost universal in a weak sense: If practitioners consider a trade-off between a slightly lower accuracy of their models and much less effort for data-fitting (compared e.g. to the general BP-model); then for 19 of our 24 data the West-model was a good choice as it had a good fit. The typical heights differed much between the twenty-four species considered in this paper. Could such difference be still compatible with the universality hypothesis?

This question leads to the second speculation mentioned above. One reason for the common growth pattern may be the setting of the growth experiment, as it could have impeded the growth of the trees in about the same way. For, the growth of all trees was sensitive to environmental factors, such as ambient temperature (see above: negative correlation). That the growth may have been impeded is suggested from the fact that for all species, except one. Table 2 displays an inflection point. This means that from this moment on, for most species within $t_{\text {inf }}=2$ to 6 years, growth began to stagnate. This is atypical for the mean heights that are normally observed for young stands with all trees still in the early growth phase. Further, the typical heights for most species (Table 1) clearly indicate much higher trees than reported in Table 2 as asymptotic heights $h_{\max }$ 


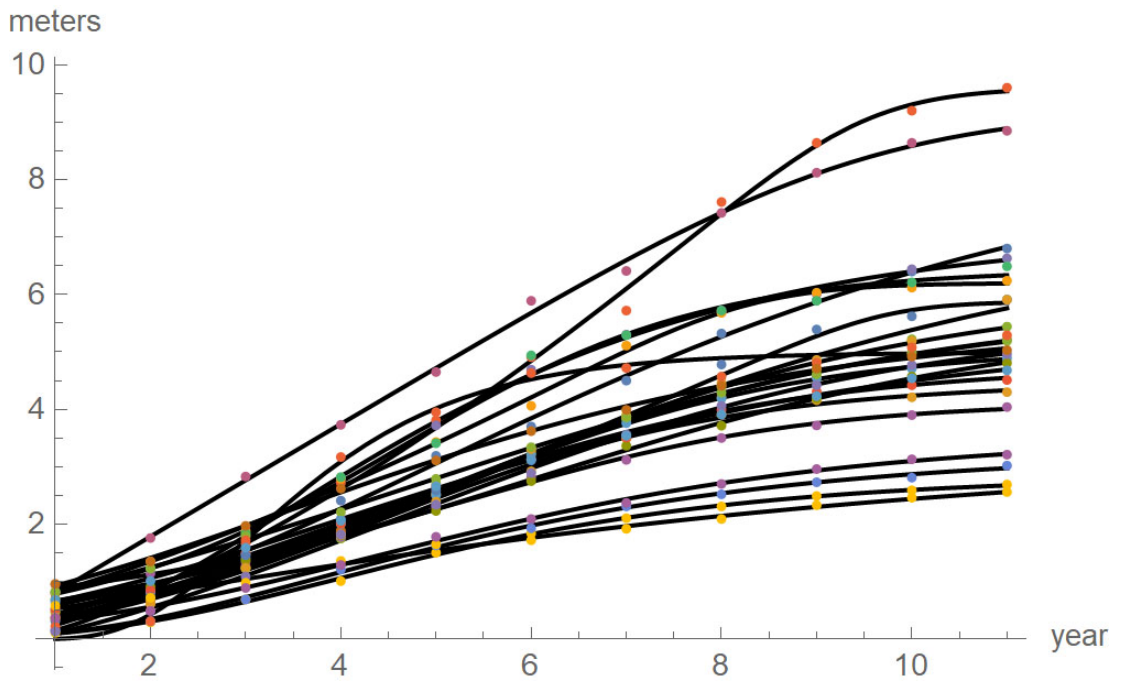

Figure 5. Data and the growth curves for all trees; plot using Mathematica 12.1.

of the 11-year time series. Thus, growth was impeded.

We therefore scrutinized the experimental setting as described in the original data sources [10] [16]. The trees have been planted in $2 \mathrm{~m}$ distance from each other on very dry red soil with $30-35 \mathrm{~cm}$ depth. A main concern was the preservation of soil moisture, which was achieved by the method of planting. Thus, there are two obvious reasons, why the growth of the trees may have beendecayed: Moisture preservation may have failed, or the selected species were not sufficiently adapted to drought. We refute these hypotheses, as such observations would have been reported in the source paper as major findings. Another conceivable explanation is competition between trees for sunlight, which might reduce height growth of suppressed trees at later stages, affecting the mean height. However, $2 \mathrm{~m}$ distance between trees below $10 \mathrm{~m}$ height usually does not affect height growth much. Thus, in an arid region there remains the explanation of competition belowground. Indeed, soil was shallow and $2 \mathrm{~m}$ distance at $30 \mathrm{~cm}$ depth result in $4 \mathrm{~m}^{2}$ per tree and about $1 \mathrm{~m}^{3}$ soil for its roots, which may not be enough for trees that have the potential to grow to heights and crown diameters of $10-30 \mathrm{~m}$. Of course, this proposed "bonsai effect" needs to be tested, but the source paper does not provide sufficient information.

We conclude that BP-models are a useful tool to analyze the height growth of trees and stands. However, the growth curves depend not only on the species but also on the environmental situation. Thereby, as for the present data, the experimental setting may curb the growth to an extent that the same model may fit to many different species.

Finally, we have added Figure 5 as a graphical summary of the paper, plotting the data in different colors and the best-fitting growth curves.

\section{Acknowledgements and Declarations}

The authors declare no competing interests. There occurred no ethical issues, as 
the research was based on published data.

\section{Conflicts of Interest}

The authors declare no conflicts of interest regarding the publication of this paper.

\section{References}

[1] Kambo, D. and Danby, R.K. (2018) Factors Influencing the Establishment and Growth of Tree Seedlings at Subarctic Alpine Tree Lines. Ecosphere, 9, e02176. https://doi.org/10.1002/ecs2.2176

[2] Dale, V.H., Doyle, T.W. and Shugart, H.H. (1985) A Comparison of Tree Growth Models. Ecological Modeling, 29, 145-169.

https://doi.org/10.1016/0304-3800(85)90051-1

[3] Hann, D.W. and Ritchie, M.W. (1988) Height Growth Rate of Douglas-Fir: A Comparison of Model Forms. Forest Science, 34, 165-175.

[4] Reynolds, J.F., Acock, B., Dougherty, R.L. and Tenhunen, J.D. (1989) A Modular Structure for Plant Growth Simulation Models. In: Pereira, J.S. and Landsberg, J.J., Eds., Biomass Production by Fast-Growing Trees, NATO ASI Series 166, Springer, Dordrecht, 123-134. https://doi.org/10.1007/978-94-009-2348-5_8

[5] Zeide, B. (1993) Analysis of Growth Equations. Forest Science, 39, 594-616. https://doi.org/10.1093/forestscience/39.3.594

[6] Brody, S. (1945) Bioenergetics and Growth. Hafner Publ. Comp., New York.

[7] Gompertz, B. (1832) On the Nature of the Function Expressive of the Law of Human Mortality, and on a New Mode of Determining the Value of Life Contingencies. Philosophical Transactions of the Royal Society of London, 123, 513-585.

[8] Verhulst, P.F. (1838) Notice sur la loi que la population suit danssonaccroissement. Correspondance Mathématique et Physique, 10, 113-121.

[9] Richards, F.J. (1959) A Flexible Growth Function for Empirical Use. Journal of EXperimental Botany, 10, 290-300. https://doi.org/10.1093/jxb/10.2.290

[10] Devaranavadgi, S.B., Bassappa, S., Jolli, R.B., Wali, S.Y. and Bagali, A.N. (2013) Height-Age Growth Curve Modelling for Different Tree Species in Drylands of North Karnataka. Global Journal of Science Frontier Research (Agriculture and Veterinary Sciences), 13, 11-21.

[11] Mischan, M.M., de Souza Passos, J.R., de Pinho, S.Z. and de Carvalho, L.R. (2015) Inflection and Stability Points of Diphasic Logistic Analysis of Growth. Scientia Agricola, 72, 215-220. https://doi.org/10.1590/0103-9016-2014-0212

[12] Schröder, J., Röhle, H., Gerold, D. and Münder, K. (2007) Modeling Individual-Tree Growth in Stands under Forest Conversion in East Germany. European Journal of Forest Research, 126, 459-472. https://doi.org/10.1007/s10342-006-0167-x

[13] Ryan, M.G. (2010) Temperature and Tree Growth. Tree Physiology, 30, 667-668. https://doi.org/10.1093/treephys/tpq033

[14] Way, D.A. and Oren, R. (2010) Differential Responses to Changes in Growth Temperature between Trees from Different Functional Groups and Biomes: A Review and Synthesis of Data. Tree Physiology, 30, 669-688.

https://doi.org/10.1093/treephys/tpq015

[15] Burkhart, H. and Tomé, M. (2012) Modeling Forest Trees and Stands. Springer, Dordrecht. https://doi.org/10.1007/978-90-481-3170-9 
[16] Devaranavadgi, S.B., Patil, S.B., Mulla, S.R., Rathod, P. and Jambagi, M.B. (2011) Evaluation of Planting Methods and Tree Species for Non-Arable Lands of Northern Dry Zone of Karnataka. International Journal of Agricultural Sciences, 7, 126-128.

[17] Pütter, A. (1920) Studien über physiologische Ähnlichkeit. VI. Wachstumsähnlichkeiten. Pflügers Archiv für die Gesamte Physiologie des Menschen und der Tiere, 180, 298-340. https://doi.org/10.1007/BF01755094

[18] Ohnishi, S., Yamakawa, T. and Akamine, T. (2014) On the Analytical Solution for the Pütter-Bertalanffy Growth Equation. Journal of Theoretical Biology, 343, 174-177. https://doi.org/10.1016/j.jtbi.2013.10.017

[19] Schnute, J. (1981) A Versatile Growth Model with Statistically Stable Parameters. Canadian Journal of Fisheries and Aquatic Sciences, 38, 1128-1140. https://doi.org/10.1139/f81-153

[20] Liu, Z.G. and Li, F.R. (2003) The Generalized Chapman-Richards Function and Applications to Tree and Stand Growth. Journal of Forestry Research, 14, 19-26. https://doi.org/10.1007/BF02856757

[21] Bertalanffy, L.V. (1949) Problems of Organic Growth. Nature, 163, 156-158. https://doi.org/10.1038/163156a0

[22] Bertalanffy, L.V. (1951) Theoretische Biologie II. Franke Verlag, Bern.

[23] Bertalanffy, L.V. (1957) Quantitative Laws in Metabolism and Growth. Quarterly Revues in Biology, 32, 217-231. https://doi.org/10.1086/401873

[24] Pienaar, L.V. and Turnbull, K.J. (1973) The Chapman-Richards Generalization of Von Bertalanffy's Growth Model for Basal Area Growth and Yield in Even-Aged Stands. Forest Science, 19, 2-22.

[25] West, G.B., Brown, J.H. and Enquist, B.J. (2001) A General Model for Ontogenetic Growth. Nature, 413, 628-631. https://doi.org/10.1038/35098076

[26] Marusic, M. and Bajzer, Z. (1993) Generalized Two-Parameter Equations of Growth. Journal of Mathematical Analysis and Applications, 179, 446-462. https://doi.org/10.1006/jmaa.1993.1361

[27] Calder, W.A. (1985) Size, Function, and Life History. Harvard Univ. Press, Cambridge.

[28] Knight, W. (1968) Asymptotic Growth, an Example of Nonsense Disguised as Mathematics. Journal of the Fisheries Research Board of Canada, 25, 1303-1306. https://doi.org/10.1139/f68-114

[29] Loibel, S., Andrade, M.G., do Val, J.B.R. and de Freitas, A.R. (2010) Richards Growth Model and Viability Indicators for Populations Subject to Interventions. Anais da Academia Brasileira de Ciências, 82, 1107-1126. https://doi.org/10.1590/S0001-37652010000400028

[30] Renner-Martin, K., Brunner, N., Kühleitner, M., Nowak, W.G. and Scheicher, K. (2018) On the Exponent in the Von Bertalanffy Growth Model. PeerJ, 6, e4205. https://doi.org/10.7717/peerj.4205

[31] Renner-Martin, K., Brunner, N., Kühleitner, M., Nowak, W.G. and Scheicher, K. (2019) Best-Fitting Growth Curves of the Von Bertalanffy-Pütter Type. Poultry Science, 98, 3587-3592. https://doi.org/10.3382/ps/pez122

[32] Brunner, N., Kühleitner, M., Nowak, W.G., Renner-Martin, K. and Scheicher, K. (2019) Comparing Growth Patterns of Three Species: Similarities and Differences. PLoS ONE, 14, e0224168. https://doi.org/10.1371/journal.pone.0224168

[33] Kühleitner, M., Brunner, N., Nowak, W.G., Renner-Martin, K. and Scheicher, K. (2019) Best Fitting Tumor Growth Models of the von Bertalanffy-Pütter Type. BMC 
Cancer, 19, Article No. 683. https://doi.org/10.1186/s12885-019-5911-y

[34] Vidal, R.V.V. (1993) Applied Simulated Annealing. Lecture Notes in Economics and Mathematical Systems. Springer-Verlag, Berlin.

https://doi.org/10.1007/978-3-642-46787-5

[35] Evans, D.L., Drew, J.H. and Leemis, L.M. (2017) The Distribution of the Kolmogorov-Smirnov, Cramer-von Mises, and Anderson-Darling Test Statistics for Exponential Populations with Estimated Parameters. In: Glen, A.G. and Leemis, L.M., Eds., Computational Probability Applications, Springer International Publishing, New York, 165-190. https://doi.org/10.1007/978-3-319-43317-2_13

[36] West, G.B., Brown, J.H. and Enquist, B.J. (1997) A General Model for the Origin of Allometric Scaling Laws in Biology. Science, 276, 122-126.

https://doi.org/10.1126/science.276.5309.122

[37] West, G.B., Brown, J.H. and Enquist, B.J. (1999) A General Model for the Structure and Allometry of Plant Vascular Systems. Nature, 400, 664-667. https://doi.org/10.1038/23251

[38] West, G.B., Brown, J.H. and Enquist, B.J. (2004) Growth Models Based on First Principles or Phenomenology? Functional Ecology, 18, 188-196. https://doi.org/10.1111/j.0269-8463.2004.00857.x

[39] West, G.B., Enquist, B.J. and Brown, J.H. (2009) A General Quantitative Theory of Forest Structure and Dynamics. Proceedings of the National Academy of Sciences, 106, 7040-7045. https://doi.org/10.1073/pnas.0812294106

[40] Rüger, N. and Condit, N. (2012) Testing Metabolic Theory with Models of Tree Growth That Include Light Competition. Functional Ecology, 26, 759-765. https://doi.org/10.1111/j.1365-2435.2012.01981.x

[41] Froese, R. and Pauly, D. (2020) FishBase. http://www.fishbase.org

[42] Pauly, D. (1981) The Relationships between Gill Surface Area and Growth Performance in Fish: A Generalization of von Bertalanffy's Theory of Growth. Meeresforschung, 28, 251-282.

[43] Roff, D.A. (1992) The Evolution of Life Histories: Theory and Analysis. Chapman and Hall, London.

[44] Slik, W.F., et al. (2015) Estimating the Number of Tropical Tree Species. Proceedings of the National Academy of Sciences, 112, 7472-7477. https://doi.org/10.1073/pnas.1423147112 